\title{
Primary Care Provider Preferences for Communication with Inpatient Teams: One Size Does Not Fit All
}

\author{
David Lawrence, MD', Aarti K. Shah, MHA', Elizabeth K. Lee, MD', Sarah J. Conway, MD1, \\ Mukund K. Ramkumar, MD', Hailey J. James, MHA',2, William S. Queale, MD, MHS', \\ Sara C. Keller, MD, MPH, MSPH' ${ }^{1}$, Elizabeth L. Biddison, MD, MPH', Peter C. Gregg, MD, MPH', \\ Bimal H. Ashar, MD, MBA', Sanjay V. Desai, MD', Daniel J. Brotman, MD', Stephen A. Berry MD, PhD*
}

'Department of Medicine, Johns Hopkins University School of Medicine, Baltimore, Maryland, United States; ${ }^{2}$ Department of Health Policy and Management, Gillings School of Global Public Health, University of North Carolina, Chapel Hill, North Carolina, United States; ${ }^{3}$ Department of Internal Medicine, Jai Medical Center, Baltimore, Maryland.

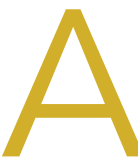

$\mathrm{s}$ the hospitalist's role in medicine grows, the transition of care from inpatient to primary care providers (PCPs, including primary care physicians, nurse practitioners, or physician assistants), becomes increasingly important. Inadequate communication at this transition is associated with preventable adverse events leading to rehospitalization, disability, and death. ${ }^{1-3}$ While professional societies recommend PCPs be notified at every care transition, the specific timing and modality of this communication is not well defined. ${ }^{4}$

Providing PCPs access to the inpatient electronic health record (EHR) may reduce the need for active communication. However, a recent survey of PCPs in the general internal medicine division of an academic hospital found a strong preference for additional communication with inpatient providers, despite a shared EHR. ${ }^{5}$

We examined communication preferences of general internal medicine PCPs at a different academic institution and extended our study to include community-based PCPs who were both affiliated and unaffiliated with the institution.

\section{METHODS}

Between October 2015 and June 2016, we surveyed PCPs from 3 practice groups with institutional affiliation or proximity to The Johns Hopkins Hospital: all general internal medicine faculty with outpatient practices ("academic," 2 practice sites, $n=$ 35), all community-based PCPs affiliated with the health system ("community," 36 practice sites, $n=220$ ), and all PCPs from an unaffiliated managed care organization ("unaffiliated," 5 practice sites ranging from 0.3 to 4 miles from The Johns Hopkins Hospital, $n=29$ ).

All groups have work-sponsored e-mail services. At the time of the survey, both the academic and community groups used an EHR that allowed access to inpatient laboratory and radiology data and discharge summaries. The unaffiliated group

\footnotetext{
*Address for correspondence: Stephen A. Berry, MD PhD, Johns Hopkins University School of Medicine, 725 N. Wolfe St, Room 217, Baltimore, MD 21205; Telephone: 443-287-4841; Fax: 410-502-7029; E-mail: sberry8@jhmi.edu
}

Received: May 10, 2017; Revised: July 20, 2017; Accepted: July 25, 2017

Published online first November 8, 2017

2018 Society of Hospital Medicine DOI 10.12788/jhm.2874 used paper health records. The hospital faxes discharge summaries to all PCPs who are identified by patients.

The investigators and representatives from each practice group collaborated to develop 15 questions with mutually exclusive answers to evaluate PCP experiences with and preferences for communication with inpatient teams. The survey was constructed and administered through Qualtrics' online platform (Qualtrics, Provo, UT) and distributed via e-mail. The study was reviewed and acknowledged by the Johns Hopkins institutional review board as quality improvement activity.

The survey contained branching logic. Only respondents who indicated preference for communication received questions regarding preferred mode of communication. We used the preferred mode of communication for initial contact from the inpatient team in our analysis. $\chi^{2}$ and Fischer's exact tests were performed with JMP 12 software (SAS Institute Inc, Cary, NC).

\section{RESULTS}

Fourteen (40\%) academic, 43 (14\%) community, and 16 (55\%) unaffiliated PCPs completed the survey, for 73 total responses from 284 surveys distributed (26\%).

Among the 73 responding PCPs, 31 (42\%) reported receiving notification of admission during "every" or "almost every" hospitalization, with no significant variation across practice groups $(P=.5)$.

Across all groups, 64 PCPs (88\%) preferred communication at 1 or more points during hospitalizations (panel A of Figure). "Both upon admission and prior to discharge" was selected most frequently, and there were no differences between practice groups $(P=.2)$.

Preferred mode of communication, however, differed significantly between groups (panel B of Figure). The academic group had a greater preference for telephone (54\%) than the community $(8 \% ; P<.001)$ and unaffiliated groups $(8 \% ; P<$ $.001)$, the community group a greater preference for EHR (77\%) than the academic $(23 \% ; P=.002)$ and unaffiliated groups $(0 \%$; $P<.001$ ), and the unaffiliated group a greater preference for fax (58\%) than the other groups (both $0 \% ; P<.001$ ).

\section{DISCUSSION}

Our findings add to previous evidence of low rates of communication between inpatient providers and $\mathrm{PCPs}^{6}$ and a pref- 

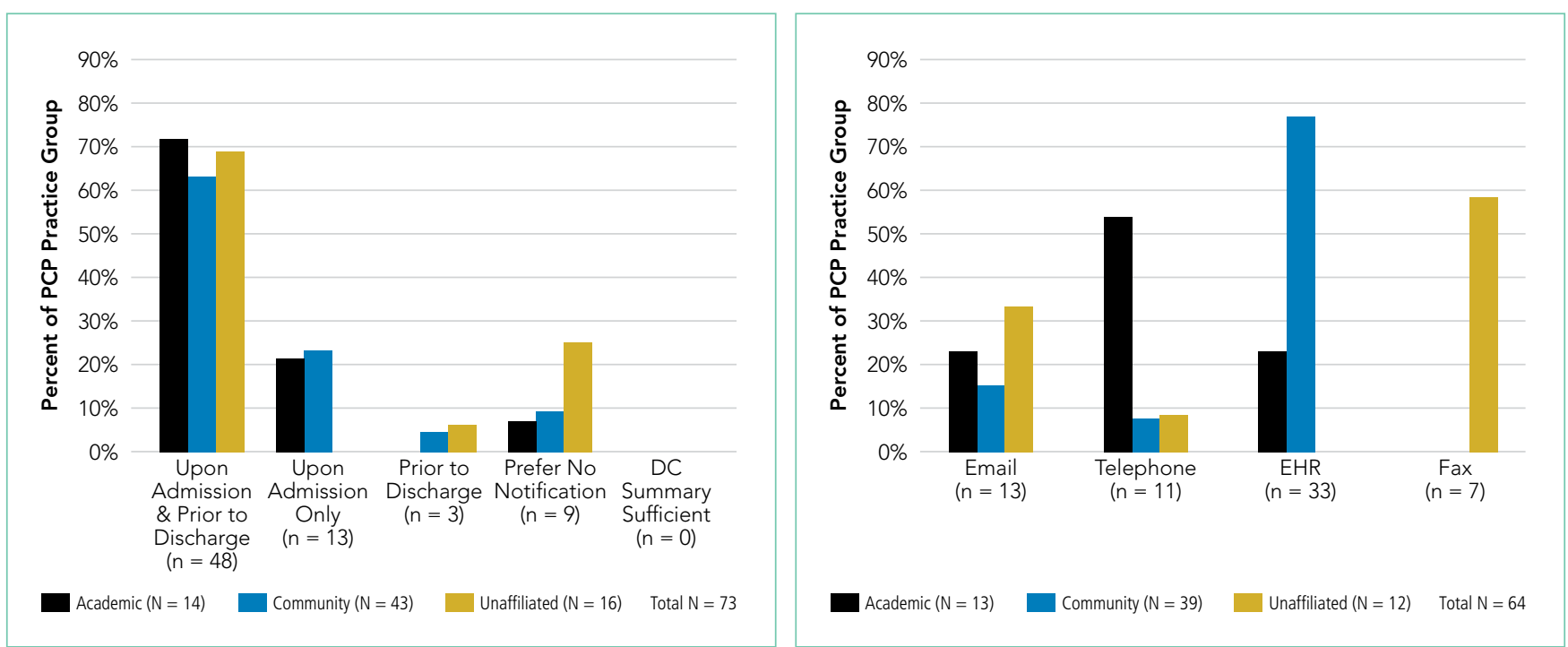

FIG. (A) PCP preferences for timing of inpatient team communication by practice group. (B) PCP preference for mode of communication by practice group. Branching logic survey design reduced total respondents to 64 , representing those who desired communication either upon admission, prior to discharge, or both.

NOTE: Abbreviation: DC, discharge; EHR, electronic health record; PCP, primary care provider.

erence from PCPs for communication during hospitalizations despite shared EHRs. ${ }^{5}$ We extend previous work by demonstrating that PCP preferences for mode of communication vary by practice setting. Our findings lead us to hypothesize that identifying and incorporating PCP preferences may improve communication, though at the potential expense of standardization and efficiency.

There may be several reasons for the differing communication preferences observed. Most academic PCPs are located near or have admitting privileges to the hospital and are not in clinic full time. Their preference for the telephone may thus result from interpersonal relationships born from proximity and greater availability for telephone calls, or reduced fluency with the EHR compared to full-time community clinicians.

The unaffiliated group's preference for fax may reflect a desire for communication that integrates easily with paper charts

\section{References}

1. Forster AJ, Murff HJ, Peterson JF, Gandhi TK, Bates DW. The incidence and severity of adverse events affecting patients after discharge from the hospital. Ann Intern Med. 2003:138(3):161-174.

2. Moore C, Wisnivesky J, Williams S, McGinn T. Medical errors related to discontinuity of care from an inpatient to an outpatient setting. J Gen Intern Med. 2003;18(8):646-651.

3. van Walraven C, Mamdani M, Fang J, Austin PC. Continuity of care and patient outcomes after hospital discharge. J Gen Intern Med. 2004;19(6):624-631.

4. Snow V, Beck D, Budnitz T, et al. Transitions of Care Consensus policy statement: American College of Physicians, Society of General Internal Medicine, Society of Hospital Medicine, American Geriatrics Society, American College and is least disruptive to workflow, or concerns about health information confidentiality in e-mails.

Our study's generalizability is limited by a low response rate, though it is comparable to prior studies. ${ }^{7}$ The unaffiliated group was accessed by convenience (acquaintance with the medical director); however, we note it had the highest response rate (55\%).

In summary, we found low rates of communication between inpatient providers and PCPs, despite a strong preference from most PCPs for such communication during hospitalizations. PCPs' preferred mode of communication differed based on practice setting. Addressing PCP communication preferences may be important to future care transition interventions.

Disclosure: The authors report no conflicts of interest.

Of Emergency Physicians, and Society for Academic Emergency M. J Hosp Med. 2009;4(6):364-370.

5. Sheu L, Fung K, Mourad M, Ranji S, Wu E. We need to talk: Primary care provider communication at discharge in the era of a shared electronic medical record. J Hosp Med. 2015;10(5):307-310.

6. Kripalani S, LeFevre F, Phillips CO, Williams MV, Basaviah P, Baker DW. Deficits in communication and information transfer between hospital-based and primary care physicians. JAMA. 2007;297(8):831-841.

7. Pantilat SZ, Lindenauer PK, Katz PP, Wachter RM. Primary care physician attitudes regarding communication with hospitalists. Am J Med. 2001(9B);111:15-20. 